\title{
Lemierre's disease: a case with bilateral iliopsoas abscesses and a literature review
}

\author{
Nicholas TE Bird ${ }^{1 *}$, Derek Cocker ${ }^{2}$, Paul Cullis ${ }^{3}$, Richard Schofield ${ }^{4}$, Ben Challoner ${ }^{1}$, Alastair Hayes ${ }^{5}$ and Martin Brett ${ }^{4}$
}

\begin{abstract}
Lemierre's disease is characterized by sepsis, often with an oropharyngeal source, secondary septic emboli and internal jugular vein thrombosis (Lancet 1:701-3, 1936. Clin Microbiol Rev 20(4):622-59, 2007). Septic emboli affecting many bodily sites have been reported, including the lungs, joints, bones, and brain. The case report describes an unusual case of Lemierre's disease in a 64 year old gentleman causing profound sepsis, acute kidney injury, bilateral iliopsoas abscesses and a right hand abscess. To our knowledge, this is the first reported case of Lemierre's disease in the context of bilateral psoas abscesses, and highlights the ambiguity surrounding the definition of Lemierre's disease. The clinical literature review highlights the difficulty in definitively diagnosing the condition and offers some suggestions for recognising and refining the diagnostic criterion of Lemierre's.
\end{abstract}

Keywords: Lemierre, Fusobacterium, Fusobacterium Necrophorum, Bilateral, Iliopsoas abscess

\section{Background}

In 1936, Lemierre described a series of lethal anaerobic septicaemias caused by the anaerobic bacterium known today as Fusobacterium necrophorum. A group of these patients suffered from "postanginal septicaemias", characterized by internal jugular vein thrombosis and septic emboli with a focus within the head and neck [1]. Septic emboli affecting many body sites have been reported, including the lungs, joints, bones, liver, brain and meninges. Septic metastasis to muscle has been described but is relatively rare [2-5]. This case report describes an unusual case of Lemierre's disease in a 64 year old gentleman causing profound sepsis, acute kidney injury, bilateral iliopsoas abscesses and a right hand abscess [6-76].

\section{Case presentation}

A 64 year old gentleman presented to the A\&E department of a district general hospital with lethargy, fever and lumbar back pain radiating to the groins of two days duration. His background included hypertension managed with multiple medications, diet controlled type 2 diabetes mellitus, chronic back pain, latent peptic ulcer disease, and bilateral total hip and knee arthroplasties.

\footnotetext{
* Correspondence: Birdnicholas1@googlemail.com

${ }^{1}$ General Surgery, University Hospital Aintree, Lower Lane, Liverpool L97AL, UK

Full list of author information is available at the end of the article
}

On examination, he was hypoxic ( $94 \%$ oxygen saturation), hypothermic $\left(35.6^{\circ} \mathrm{C}\right)$ and tachycardic with new onset, fast atrial fibrillation (rate 142/minute), but normotensive. In addition, he was diffusely tender in the supra-pubic region and in both loins, especially on the right. Neurological examination was normal other than MRC grade $4 / 5$ power in the lower limbs.

Blood tests demonstrated a marked inflammatory response with raised CRP $(373 \mathrm{mg} / \mathrm{L})$ and predominantly neutrophilic leucocytosis $\left(20.5 \times 10^{9} / \mathrm{L}\right)$. Acute kidney injury (urea $31.4 \mathrm{mmol} / \mathrm{L}$; creatinine $244 \mu \mathrm{mol} / \mathrm{L}$ ) and mildy deranged liver function tests (alkaline phosphatase $343 \mathrm{IU} / \mathrm{L} ;$ GGT $183 \mathrm{IU} / \mathrm{L} ;$ ALT $52 \mathrm{IU} / \mathrm{L} ;$ bilirubin $14 \mu \mathrm{mol} / \mathrm{L}$ ) were evident. Arterial blood gases demonstrated a metabolic acidosis ( $\mathrm{pH} 7.32$; base excess $-8 \mathrm{mEq} / \mathrm{L}$ ). A chest radiograph was normal. Urinalysis was positive for leucocytes and erythrocytes only. Blood cultures were taken and broad spectrum antibiotics were commenced for presumed urosepsis.

24 hours after admission, the right hand became diffusely swollen, erythematous and tender, and the patient continued to experience pyrexia. His urine cultures yielded Serratia marcescens sensitive to the antibiotics. Ultrasonography of the urinary tract failed to demonstrate hydronephrosis. Ultrasonography of the right hand showed generalised soft tissue oedema with a $1 \mathrm{~cm}$ deep fluid filled collection containing echogenic material overlying the MCP joints. 
The following day, the acute kidney injury worsened (urea $43.4 \mathrm{mmol} / \mathrm{L}$; creatinine $351 \mu \mathrm{mol} / \mathrm{L}$ ). An urgent CT thorax/abdomen/pelvis demonstrated an unexpected finding of bilateral iliopsoas abscesses, most extensive on the right side which contained a considerable volume of gas (Figures 1 and 2).

The patient proceeded to theatre for drainage of the abscesses. During intubation the anaesthetist noted the oropharynx was sloughy and inflamed and accordingly biopsies were taken. Bilateral groin incisions were used to approach the iliopsoas muscles in the extra-peritoneal plane. On the right side the abscess cavity involved the entire length of the iliopsoas muscle and contained $100 \mathrm{ml}$ of cream coloured pus as well as gas. On the left side an estimated $40 \mathrm{ml}$ of pus was contained within the lower psoas muscle. There was no evidence of communication with the replaced hip joints on either side. Drains were placed into the cavities. The hand abscess was also drained and samples from all sites were sent to microbiology. The patient was then transferred postoperatively to ICU for inotropic support (noradrenaline) and ongoing fluid resuscitation.

72 hours after admission the blood cultures returned a yield of F. necrophorum and subsequently tazocin and metronidazole were commenced. He remained intubated for a further three days. An echocardiogram was largely unremarkable. The oropharyngeal biopsies demonstrated, particularly in the vallecula, acute-on-chronic infection but no discrete microbial growth was achieved. The other microbiological samples did not yield any growth on extended culture runs. Subsequent neck

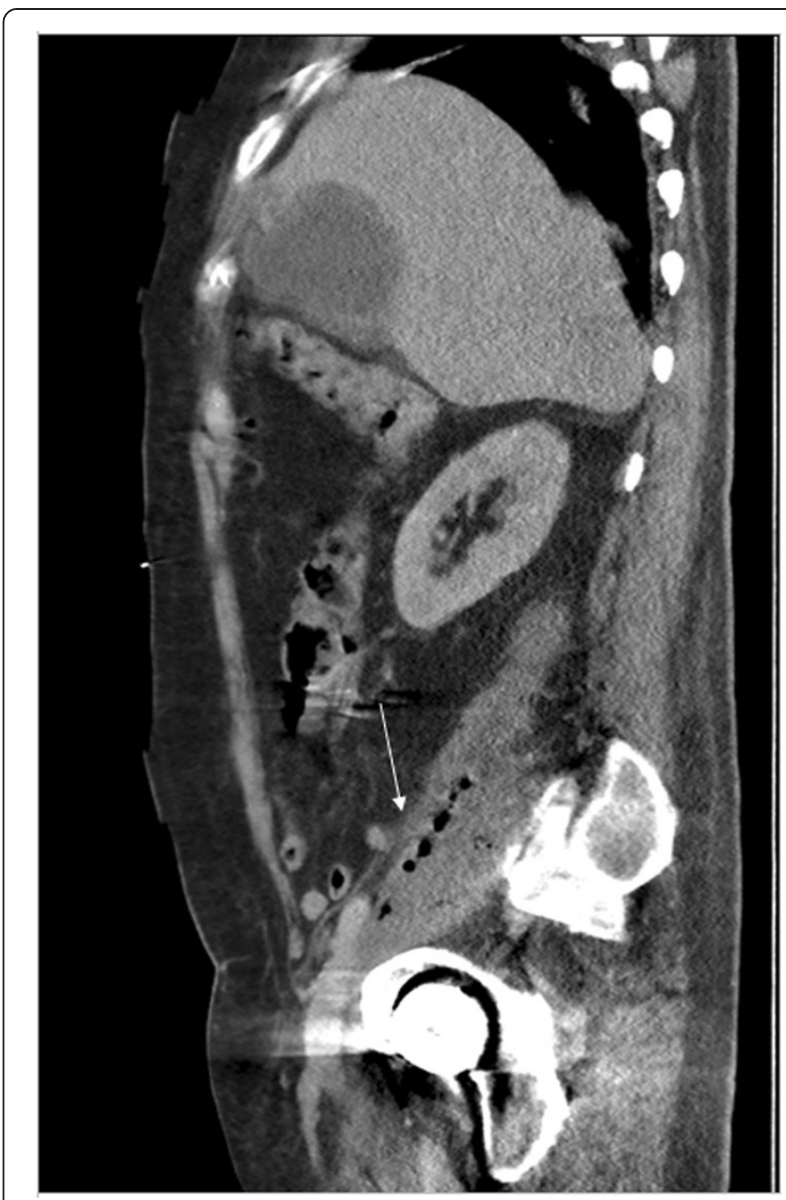

Figure 2 CT demonstrated Sagittal View of Abdomen and Pelvis demonstrating gas locules in Right Iliopsoas Region.

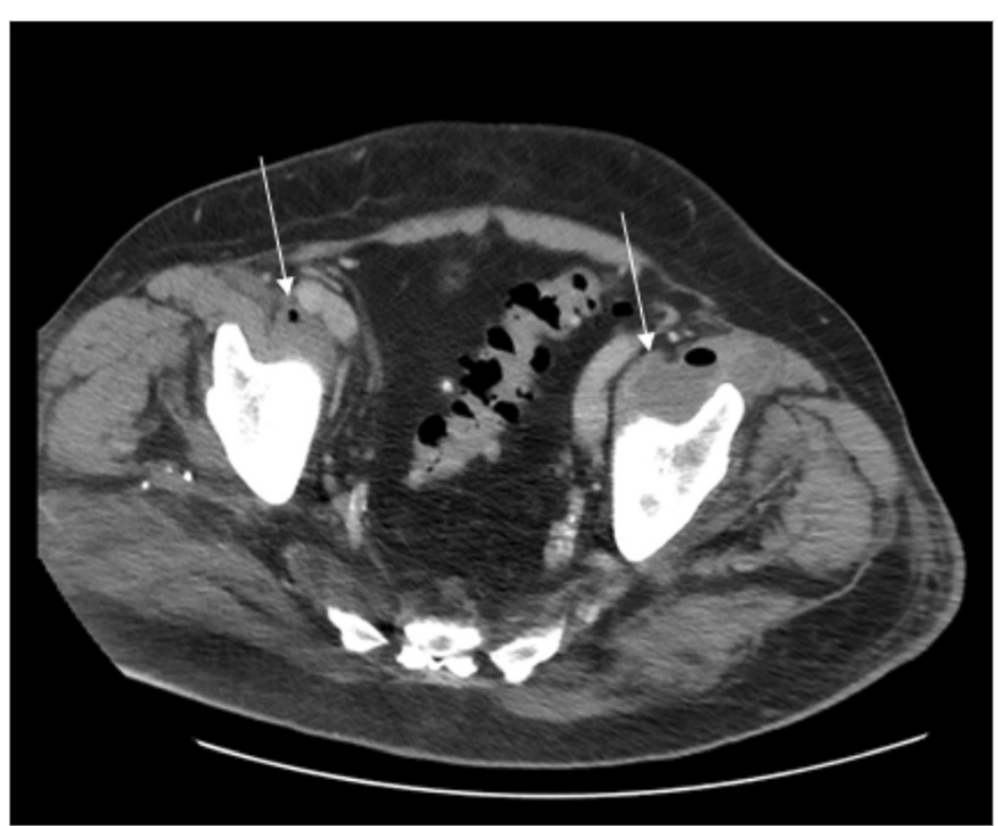

Figure 1 Transverse view on CT of the bilateral iliopsoas abscesses. 


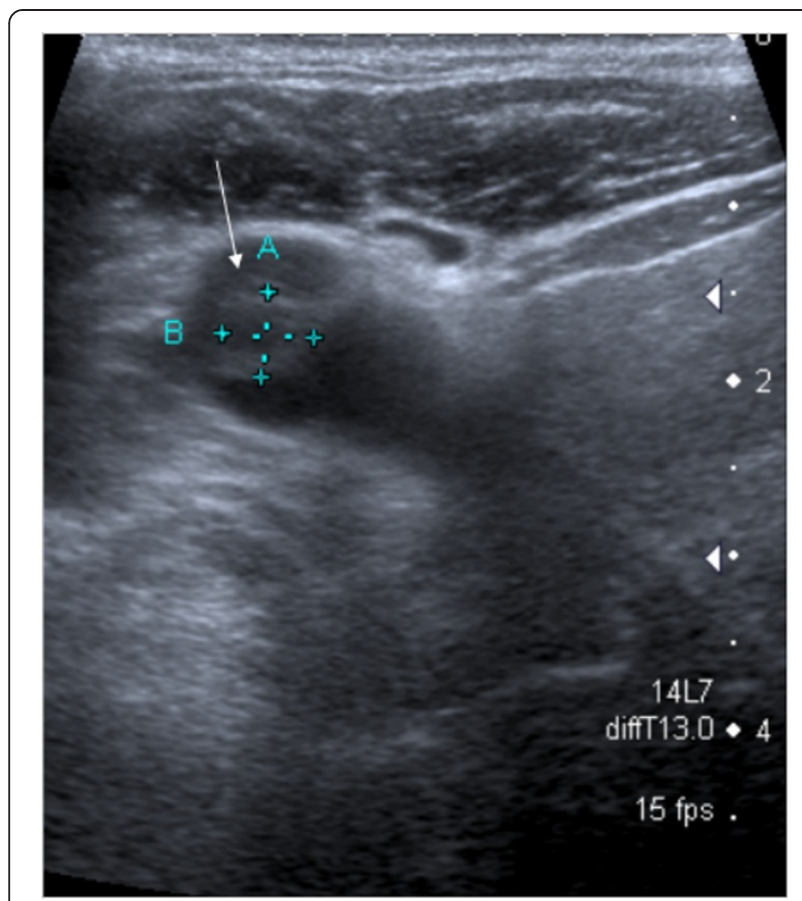

Figure $3>50 \%$ occlusive right internal jugular vein thrombus on ultrasonography.

ultrasonography confirmed a partially occlusive right internal jugular vein thrombus at the subclavian confluence (Figure 3). A CT neck/thorax confirmed this but did not demonstrate other occult pathology. Anticoagulation therapy with warfarin was subsequently commenced. The patient is now well and not suffering from any residual disability.

\section{Discussion}

Despite reports of human illnesses caused by what is now known as $F$. necrophorum appearing within early $20^{\text {th }}$ Century literature, the consensus definition of Lemierre's syndrome remains unclear [5,77]. The authors undertook a literature review to further clarify these diagnostic criteria. Using the PubMed search engine we utilised the following mesh headings: Lemierre's (All Text); and Fusobacterium (All Text); and Case (Title/Abstract).

The search yielded 96 papers published since 1980 from a wide global geographical area inclusive of Asia, South America, North America and Europe. The authors used only papers which had symptomatic descriptions, bacteriological evidence, radiological evidence and descriptions in English which could possibly demonstrate a definitive diagnosis of Lemierre's disease. This left 78 identifiable cases in the literature.

Analysis of the 78 cases demonstrates that the oropharynx tends to be the primary infective site with 59/78 (77\% - see Table 1) of all cases demonstrating symptoms prior to sepsis of an acute oropharyngeal infection. $16 / 78$ (21\%) of the remaining cases had primary infective sites from other anatomical locations. 5/78 (6\%) of these cases originated in the ears with symptoms of otitis externa occurring prior to widespread sepsis. 3/78 (4\%) cases originated in the soft tissues in the neck from originally superficial infections of the skin in both the anterior $(2 / 3$ cases $)$ and the posterior $(1 / 3$ cases) triangles. $3 / 78$ (4\%) of cases had syndromic components but no obvious primary infective site.

A particularly contentious aspect is whether or not the presence of thrombophlebitis of the internal jugular vein is essential in the diagnosis [77]. In our case, ultrasound and CT confirmed the presence of substantial internal jugular vein (IJV) thrombus. Our literature review demonstrated 54/78 (69\% - see Table 2) of reported cases had thrombus in the IJV. In $2 / 78(3 \%)$ of cases the IJV thrombus propagated cranially resulting in thrombophlebitis of the cranial veins. In both cases there were headache symptoms but no dynamic neurology. 18/78 (23\%) of patients had thrombophlebitis in other anatomical locations which correlated with an ipsilateral local primary infective site. An unusual example of this is a case of thrombophlebitis of the ovarian vein in a case of fusobacterial sepsis from an Intra-Uterine Device [30]. 4/18 (22\%) of these cases involved peritonsillar abscesses with ipsilateral facial vein involvement and substantial cellulitis of the face and neck region. 6/18 (33\%) of cases of alternative anatomical sites for thrombophlebitis were the great veins of the cranium with the cavernous sinus and the sigmoid sinus being involved individually in $1 / 18$ (5\%) cases respectively. There were $2 / 18$ (11\%) cases of clot propagation distally from the cavernous sinus to the sigmoid sinuses. 1/18 (5\%) cases demonstrated thrombophlebitis in the vasculature near the site of infective metastasis indicating that fusobacterial sepsis produces a highly pro-coagulant inflammatory response in patients [60]. This effect is demonstrated in the $2 / 78$

Table 1 Site of primary infection

\begin{tabular}{|c|c|c|c|c|}
\hline & Oropharynx & Cranio-facial & Extra cranio-facial & Unknown \\
\hline \multirow[t]{4}{*}{ Number of cases reported } & $N=59$ & $N=13$ & $N=3$ & $N=3$ \\
\hline & & 5 Ear & 1 Spine & \\
\hline & & 5 Dental & 1 Uterus & \\
\hline & & 3 Neck & 1 Hand & \\
\hline
\end{tabular}


Table 2 Site of thrombus formation

\begin{tabular}{|c|c|c|c|c|}
\hline & Internal jugular vein & Alternative vessel & Negative for thrombus & Unknown \\
\hline \multirow[t]{10}{*}{ Number of cases reported } & $N=54$ & $N=22$ & $N=3$ & $N=8$ \\
\hline & & 6 Sigmoid Sinus & & \\
\hline & & 4 Facial Vein & & \\
\hline & & 4 Cavernous Sinus & & \\
\hline & & 2 External Jugular Vein & & \\
\hline & & 2 Carotid Artery & & \\
\hline & & 1 Subclavian Vein & & \\
\hline & & 1 Axillary Vein & & \\
\hline & & 1 Hepatic Vein & & \\
\hline & & 1 Ovarian Vein & & \\
\hline
\end{tabular}

(3\%) cases where there was thrombus formation within the carotid artery [45,61], a vessel with typically very high laminar flows which, according to Virchow's triad, would preclude against clot formation and aggregation.

The 78 individual patients produced 105 metastatic abscess sites indicating that multiple sites of metastases are a common feature of Lemierre's syndrome (see Table 3). The most common site of metastasis is to the lungs which occurred in 55/105 (52\%) metastatic sites and 55/78 (70\%) of individual cases. 10/105 (9\%) of metastases occurred in other soft tissue areas, of which $7 / 10$ (70\%) had concomitant pulmonary metastases. $6 / 105$ (5\%) metastatic sites were in the joints with $2 / 6$ (33\%) of these having associated pulmonary metastases. $18 / 105$ (17\%) metastases were to solid organs and bones. $12 / 18$ (69\%) soft tissue metastases occurred with pulmonary metastases. Therefore 21/55 (37\%) of patients with pulmonary metastases developed further metastatic abscesses throughout the body with the most common metastases being to solid organs in $12 / 21$ cases (60\%). $12 / 18(67 \%)$ of the metastases were to the cranial vault including cerebral (4/12), subdural (3/12) and epidural $(2 / 12)$ anatomical locations. $4 / 12$ (33\%) of the cranial vault metastases had no pulmonary metastases. All of these cases had extensive cranial vein thrombophlebitis and, in 1 case, carotid artery thrombus.

The primary method of treatment of Lemierre's Syndrome is through the use of broad-spectrum antimicrobials and supportive treatment. Surgery was utilised as a treatment modality in 24/78 (31\%) cases in an attempt to gain source control in patients with refractory sepsis. Despite the presence of extensive pulmonary metastases which would make anaesthesia more dangerous, the surgical cohort had a $0 \%$ mortality rate while the overall cohort had a mortality rate of $4 / 78(5 \%) .3$ of the fatal cases were at the extremes of age, being 79 [18], 80 [50] and 10 years old respectively [43], with multiple metastatic sites and severe sepsis. The remaining fatality was a 34 year old gentleman with a delayed presentation to hospital one week postonset of systemic symptoms with metronidazole resistant fusobacterial sepsis and multiple metastatic sites including heart valve vegetations [14]. Although this cohort is small

Table 3 Site of metastatic spread and progression to surgery

\begin{tabular}{|c|c|c|c|c|}
\hline & Pulmonary & Soft tissue & Articular & Solid organ/bone \\
\hline \multirow[t]{9}{*}{ Number of cases reported } & $N=55$ & $N=10$ & $N=6$ & $N=22$ \\
\hline & & 2 Mediastinal & $2 \mathrm{Hip}$ & 10 CNS \\
\hline & & 1 Masseter & $1 \mathrm{TMJ}$ & 3Endocardial \\
\hline & & 1 Parotid & $1 \mathrm{C} 1 / \mathrm{C} 2$ & 3 Liver \\
\hline & & 1 Shoulder & 1 Knee & 2 Orbital \\
\hline & & 1 Ear & 1 Shoulder & 2 Solid Bone \\
\hline & & 1 Neck & & 1 Kidney \\
\hline & & 1 Subphrenic & & 1 Pericardial \\
\hline & & 1 Leg & & \\
\hline Progression to surgery & 9 & 2 & 1 & 4 \\
\hline Mortality & 2 & 0 & 0 & 2 \\
\hline
\end{tabular}


it would seem to indicate that the outcomes are poorer for patients with reduced physiological reserve, locally advanced inflammation and multiple metastatic sites.

\section{Conclusion}

Riordan has previously highlighted the epistemological difficulty in definitively diagnosing Lemierre's as a distinct disease entity [77]. Indeed there are numerous terms and diagnostic classifications utilised inchoately by multiple authors but Riordan argues that Lemierre's should be confined to fusobacterium necrophorum sepsis originating in the oropharynx. While we cannot conclusively prove that in our case profound fusobacterial sepsis originated as a consequence of oropharyngeal infection, the biopsies taken of the oropharynx do demonstrate an acute-on-chronic inflammation which would fit with the subsequent clinical manifestation of Lemierre's Syndrome. The anaerobic blood cultures grew fusobacterium necrophorum which is the vital component for a diagnosis of Lemierre's disease and is the only consistent component of the three general terms of necrobacillosis, post-anginal sepsis and Lemierre's syndrome utilised in the medical literature.

The presence of substantial IJV thrombosis in our case, while consistent with the literature, is controversial with respect to the fact that the patient had had a central venous catheter inserted for 3 days on ICU prior to appropriate radiological investigations of the neck and therefore the provenance of the thrombus is contestable. There is debatable evidence regarding the length of time a central venous catheter needs to be in situ before occlusive thrombus forms. Some studies have suggested that less than 3 days with a central catheter in-situ can cause small thrombus formation [6,7]. However other equally robust studies have suggested that a central venous catheter needs to be in-situ for approximately 11 days to develop extensive occlusive thrombus [8] as demonstrated in our case. The literature review demonstrated that $31 \%$ of all cases did not have thrombosis of the IJV, however there were only $3 / 78(4 \%)$ of cases with no associated thrombosis. Therefore thrombosis in the presence of fusobacterial bacteraemia would be a more appropriate diagnostic criterion than defining the disease by specific anatomically located thromboses.

In the context of the literature our case was unusual in that it demonstrated unique anatomical variation of the metastases and required surgery as the primary modality of treatment. Our patient did not have any pulmonary metastases which some authors have argued is a key diagnostic criterion for Lemierre's syndrome [5]. However, our literature review has demonstrated that $30 \%$ of the cases had no pulmonary involvement. In view of this fact the authors support Riordan's suggestion that Lemierre's Syndrome should be reconstituted as fusobacterium necrophorum sepsis, however with the additional diagnostic criterion of the presence of thrombosis. It would seem that the septic metastases are a common complication of the syndrome with huge anatomical variation and as such are not essential to diagnose the condition.

\section{Consent}

Written informed consent was obtained from the patient for publication of this Case report and any accompanying images. A copy of the written consent is available for review by the Editor-in-Chief of this journal.

\section{Abbreviations}

CRP: C - Reactive Protein; Mg/l: milligrams per litre; $\mu$ mol/L: micromols per litre; $\mathrm{mmol} / \mathrm{L}$ : millimols per litre; IU/L: International Units per litre;

GGT: gamma glutamyl-transpeptidase; ALT: Alanine Aminotransferase; CT: Computed Tomography; MCP: Metacarpophalangeal; ICU: Intensive Care Unit; IJV: Internal Jugular Vein.

\section{Competing interests}

The author declares that they have no competing interest.

\section{Authors' contributions}

NTEB: Recognised the uniqueness of presentation. Acquired background sources. Primary information analyst. Main writer of case. Read and approved the content of the case. PC: Additional background sources. Secondary writer. Read and approved the case content. DC: Additional background knowledge. Secondary writer. Proof read case. Edited for submission. BC: Additional background research and paper sourcing for literature review. RS: Image acquisition. Anonymised radiographic data. $\mathrm{AH}$ : Additional key source acquisition. Proof read and helped edit paper. MB: Consultant surgeon responsible for overall patient care and patient data. Read and approved manuscript. All authors read and approved the final manuscript.

\section{Author details}

'General Surgery, University Hospital Aintree, Lower Lane, Liverpool L97AL, UK. ${ }^{2}$ Infectious Diseases, Royal Liverpool Hospital, Prescot Street, Liverpool L7 8XP, UK. ${ }^{3}$ General Surgery, Royal Liverpool Hospital, Prescot Street, Liverpool L7 8XP, UK. ${ }^{4}$ General Surgery, Warrington Hospital, Lovely Lane, Warrington WA5 1QG, UK. ${ }^{5}$ General Surgery, Royal Infirmary of Edinburgh, 51 Little France Crescent Old Dalkeith Road, Edinburgh EH16 4SA, UK.

Received: 26 February 2014 Accepted: 17 April 2014 Published: 15 May 2014

\section{References}

1. Lemierre A: On certain septicemias due to anaerobic organisms. Lancet 1936, 1:701-703.

2. Kleinman PK, Flowers RA: Necrotising pneumonia after pharyngitis due to Fusobacterium necrophorum. Paediatr Radiol 1984, 14(1):49-51.

3. Park D, Rezajooi K, Sabin I: Lemierre's syndrome an unusual manifestation of spinal infection. J Bone Joint Surg, Br Vol 2006, 88(2):261-262.

4. Saed S, Zafar U, Johnson LB: Fusobacterium causing concomitant liver and brain abscesses. Infect Dis Clin Pract 2005, 13(5):265-267.

5. Karkos PD, Asrani S, Karkos CD, Leong SC, Theochari EG, Alexopoulou EG, Assimakopoulos AD: Lemierre's syndrome: a systematic review. Laryngoscope 2009, 119(8):1552-1559.

6. Kujur R, Rao SM, Badwaik G, Paraswani R: Thrombosis associated with right internal jugular central venous catheters: A prospective observational study Indian. J Crit Care Med 2012, 16(1):17-21.

7. Van Rooden CJ, Tesselaar MET, Osanto S, Rosendaal FR, Huisman MV: Deep vein thrombosis associated with Central Venous Catheters; a review. J Thromb Haemost 2005, 3:2409-2419.

8. Lordick F, Hentrich M, Decker T, Hennig M, Pohlman H, Hartenstein R, Peschel C: Ultrasound screening for internal jugular vein thrombosis aids the detection of central venous catheter-related infections in patients with haemato-oncological diseases: a prospective observational study. Br J Haematol 2003, 120(6):1073-1078. 
9. Gupta N, Kralovic SM, McGraw D: Lemierre syndrome: not so forgotten! Am J Crit Care 2014, 23(2):176-179.

10. Marulasiddappa $V$, Tejesh CA: Lemierre's syndrome presenting with septic shock Indian. J Crit Care Med 2013, 17(6):382-384

11. Kim T, Choi JY: Lemierre syndrome with thrombosis of sigmoid sinus following dental extraction: a case report. J Korean Assoc Oral Maxillofac Surg 2013, 39(2):85-89.

12. Phua CK, Chadachan VM, Acharya R: Lemierre syndrome - should we anticoagulate? A case report and review of the literature. Int J Angiol 2013, 22(2):137-142.

13. Cherpillod Traschel J, Maestre LA, Gudinchet F: Imaging of Lemierre's in children and young adults. Praxis 2013, 102(25):1519-1527.

14. Moore C, Addison D, Wilson JM, Zeluff B: First case of fusobacterium necrophorum endocarditis to have presented after the $2^{\text {nd }}$ decade of life. Tex Heart Inst J 2013, 40(4):449-452.

15. Dubois G, Damas F, Fraipont V: Clinical case of the month: an unusual sepsis. Rev Medi Liege 2013, 68(7-8):387-390.

16. Blessing K, Toepfner N, Kinzer S, Mollmann C, Serr A, Hufnagel M, Muller C, Kruger M, Ridder GJ, Berner R: Lemierre syndrome associated with $12^{\text {th }}$ cranial nerve palsy - a case report and review. Int J Paediatr Otorhinolaryngol 2013, 77(9):1585-1588.

17. Abhishek A, Sandeep S, Tarun P: Lemierre syndrome from a neck abscess due to methicillin resistant staphylococcus aureus. Brazillian J Infect Dis 2013, 17(4):507-509.

18. Righini CA, Karkas A, Tournaire R, N'Gouan JM, Schmerber S, Reyt E, Atallah I: Lemierre syndrome: a study of 11 cases and literature. Rev Head Neck 2013, Online Publication: doi:10.1002/hed.23410.

19. DeGaffe GH, Murphy JR, Butler IJ, Shelburne J, Heresi GP: Severe narrowing of left cavernous carotid artery associated with Fusobacterium necrophorum infection. Anaerobe 2013, 22:118-120.

20. Wahab D, Bichard J, Shah A, Mann B: Just a sore throat? Uncommon causes of significant respiratory disease. Br Med J Case Rep 2013, Online Publication: doi:10.1136/bcr-2013-008739.

21. Paul SP, Beri R, Linney MJ: Lemierre's syndrome: a sinister sore throat every clinician should remember Turkish. J Paediatr 2012, 54(5):528-531.

22. Ramos A, Berbari $E_{1}$ Huddleston P: Diagnosis and treatment of Fusobacterium nucleatum disciitis and vertebral osteomyelitis: a case report and review of the literature. Spine 2013, 38(2):120-122.

23. Lim AL, Pua KC: Lemierre syndrome medical. J Malays 2012, 67(3):340-341.

24. Tsai YJ, Lin YC, Harnnd DJ, Chiang RP, Wu HM: A Lemierre syndrome variant caused by Klebsiella pneumoniae. J Formosan Assoc 2012, 111(7):403-405.

25. Iwasaki T, Yamamoto T, Inoue K, Takaku K: A case of Lemierre's syndrome in association with liver abscess without any other metastatic lesions. Intern Med 2012, 51(11):1419-1423.

26. Kuppalli K, Livorsi D, Talati NJ, Osborn M: Lemierre's syndrome due to Fusobacterium necrophorum. Lancet Infect Dis 2012, 12(10):808-815.

27. Hsu YP, Tsai SH, Li LY: Isolated septic arthritis of the hip secondary to Fusobacterium necrophorum. Am J Med Sci 2012, 343(3):262-264.

28. Price $K$, Wilson $L$, Tsegaye M: A case of craniocervical abscess with sinus thrombosis in Lemierre's syndrome. Br J Neurosurg 2012, 26(3):426-428.

29. Yamamoto E, Fukae T, Kawai Y, Kamio M, Fukumi S, Nakagawa M, Matsunaga K, Numata Y: Case of Fusobacterium necrophorum sepsis (Lemierre's syndrome) with pulmonary septic emboli and liver abscess. Nihon Rinsho Meneki Gakkai Kaishi 2011, 34(5):431-437.

30. Huynh-Moynot S, Commandeur D, Deserts MD, Drouillard I, Leguen P, Ould-Ahmed M: Septic shock Fusobacterium necrophorum from gynaecological origin with complicated acute respiratory distress syndrome: a variant of Lemierre's syndrome. Ann Clin Biol 2011, 69(2):202-207.

31. Kisser U, Gurkov R, Flatz W, Berghaus A, Reichel O: Lemierre syndrome: a case report. Am J Otolaryngol 2012, 33(1):159-162.

32. Courtin P, Toro A, Gazagnes M, Berrouba A, Gallardo M, Dembele A: Lemierre's syndrome. French Ann Anaesthesiol 2010, 29(11):799-802.

33. Harris JD, Kaeding CC, Flanigan DC, Naylor AR, Ellis TJ: Severe musculoskeletal infection variant in Lemierre's syndrome. Orthopaedics 2010, 33(10):774.

34. Rm C, Geiger P, Waites KB: Fusobacterium Necrophorum Bactaraemic tonsillitis: 2 cases and a review of the literature. Anaerobe 2010 16(6):626-628

35. Heimgartner B, Knecht $U$, Oestmann A: Fever and dysphagia of a young woman. Praxis 2010, 99(14):859-862.
36. Chacko EM, Krilov LR, Patten W, Lee PJ: Lemierre's and Lemierre's-like syndromes in association with infectios mononucleosis. J Laryngol Otol 2010, 124(12):1257-1262

37. Teng HW, Chen CY, Chen HC, Chung WT, Lee WS: Fusobacterium septicaemia complicated by cerebral subdural and epidural empyema's: a rare case of Lemierre syndrome. J Emerg Med 2012, 43(4):671-673.

38. Aouad R, Melkane A, Rassi S: Lemierre syndrome: unusual cause and presentation. Paediatr Emerg Care 2010, 26(5):376-377.

39. Dirks J, Bowie D: Sore throat progressing to embolic sepsis: a case of Lemierre's syndrome. Can Respir J 2010, 17(1):20-22.

40. Boldt BM, Nguyen D, Faga M, Caras W: Lemierre syndrome: from pharyngitis to fulminant Sepsis. BMJ Case Rep 2010, Online Publication: doi:10.1136/bcr.06.2010.3121.

41. Braunbeck A, Geiger EV, Weber R, Maier M, Daecke W, Fiebig C, Marzi I: Phlegmon of the palm of the hand as initial manifestation of the Lemierre syndrome. UnfallChirurgica 2010, 113(2):155-158.

42. Ridgway JM, Parikhh DA, Wright R, Holden P, Armsrong W, Camilon F, Wong $B J$ : Lemierre syndrome: a paediatric case series and review of the literature. Am J Otolaryngol 2010, 31(1):38-45.

43. Gilbert JD, Warner S, Byard RW: Lemierre syndrome and unexpected death in childhood. J Forensic Leg Med 2009, 16(8):476-481.

44. Ramadan HK: A vanishing disease can still happen. Emerg Med J 2009, 26(10):749.

45. Goyal MK, Kumar G, Burger R: necrobacillosis resulting in isolated carotid thrombosis and massive stroke: a unique Lemierre variant. J Neurol Sci 2009, 287(1-2):108-110.

46. Bilal M, Cleveland KO, Gelfand MS: Community-acquired methicillinresistant staphylococcus aureus and Lemierre syndrome. Am J Med Sci 2009, 338(4):326-327.

47. Velagapudi P, Turagam M, Patel H, Yekkirala L: 'A forgotten disease': a case of Lemierre syndrome. Scientific World J 2009, 20(9):331-332.

48. Ogugua C: Bilateral Lemierre syndrome secondary to periodontitis: a case report and review of the literature. J Brochol Intervent Pulmonol 2009, 16(2):115-120

49. Hile LM, Gibbons MD, Hile DC: Lemierre syndrome complicating otitis externa: case report and literature review. J Emerg Med 2012, 42(4):77-80.

50. Gokce-Ceylan B, Yavuz L, Baydar CL, Tuz M, Eroglu F, Kiris I, Akcam FZ, Erdem B: Lemierre syndrome: a case of a rarely isolated micro-organism staphylococcus aureus. Med Sci Monit 2009, 15(3):58-61.

51. Alherabi A: A case of Lemierre syndrome. Ann Saudi Med 2009, 29(1):58-60

52. Lu MD, Vasayada Z, Tanner C: Lemierre syndrome following oropharyngeal infection: a case series. J Am Board Fam Med 2009, 22(1):79-83.

53. Abourazzak S, Zouagui A, Smaili L, Ouzaa H, Lamrani YM, Tizniti S, Elargam L, Chaouki S, Atmani S, Hida M: Lemierre syndrome: once seen it can never be mistaken. BMJ Case Rep 2009, Online Publication: doi:10.1136/ bcr.10.2008.1041.

54. O'Dwyer DN, Ryan S, O'Keefe T, Lyons J, Layelle L, McKone E: Lemierre's syndrome. Ir J Med Sci 2011, 180(2):556-557.

55. Passalidou P, Berlioz M, Bailly C, Boutte P: Lemierre syndrome: a complication of an oropharyngeal infection. Arch Paediatr 2008, 15(12):1775-1778.

56. Aspesberro F, Siebler $T$, Van Nieuwenhuyse JP, Panosetti E, Berthet $F$ : Lemierre syndrome in a 5-month-old male infant: case report and review of the paediatric literature paediatric. Crit Care Med 2008, 9(5):35-37.

57. Seo YT, Kim MJ, Kim JH, Ha BW, Choi HS, Kim YT, Ham YH: Lemierre syndrome: a case of postanginal sepsis. Korean J Intern Med 2007, 22(3):211-214

58. Juarez El, Diaz CA, Aboul-Hons CS, Monner DA, Mari RA, Arranz OC, Piulachs CP, Lluch SJM, Cusco AS, Sieira GR: Lemierre syndrome associated with dental infections: report of one case and review of the literature. Med Oral Pathol Oral y Cirugica Buccal 2007, 12(5):394-396.

59. Syed MI, Baring D, Addidle M, Murray C, Adams C: Lemierre syndrome 2 cases and a review. Laryngoscopy 2007, 117(9):1605-1610.

60. Cheung WY, Bellas J: Case report: Lemierre syndrome presenting with fever and pharyngitis. Am Fam Physician 2007, 75(7):979-980.

61. Waterman JA, Balbi HJ, Vaysman D, Ayres RA, Caronia CG: Lemierre syndrome: a case report. Paediatr Emerg Care 2007, 23(2):103-105.

62. Westhout F, Hasso A, Jalili M, Afghani B, Armstrong W, Nwagwu C, Ackerman LL: Lemierre syndrome complicated by cavernous sinus thrombosis with 
development of subdural empyema's and internal carotid artery narrowing without cerebral infarction: a case report. J Neurosurg 2007, 106(1):53-56.

63. Duong M, Wenger J: Lemierre syndrome. Paediatr Emerg Care 2005, 21(9):589-593.

64. Nadkarni MD, Verchick J, O'Neill JC: Lemierre syndrome. J Emerg Med 2005, 28(3):297-299

65. Sibaj K, Surasin F: Lemierre syndrome: a diagnosis to keep in mind. Rev Med Suisse Romande 2004, 124(11):693-695.

66. Hayashi M, Yamawaki I, Nakata J, Watanabe N, Ohkawa S: A case of Lemierre syndrome. Nihon Kokyuki Gakkai Zasshi 2003, 41(9):651-654.

67. Klinge L, Vester U, Schaper J, Hoyer PF: Severe Fusobacteria infections (Lemierre syndrome) in 2 boys. Eur J Paediatr 2002, 161(11):616-618.

68. Lacaze O, Bocquel V, Fournel P, Emonot A: Lemierre syndrome: clinical and radiological characteristics of a rare disease. Revues de Maladies de Respiratoire 2000, 17(6):1105-1106.

69. Screaton NJ, Ravenel JG, Lehner PJ, Heitzman ER, Flower CD: Lemierre syndrome: forgotten but not extinct - report of 4 cases. Radiology 1999, 213(2):369-374.

70. Bouton F, Cotils M, Genard M, Hubert C: Septic thrombophlebitis of the internal jugular vein and Lemierre syndrome. Revue Med de Bruxelles 1998, 19(1):5-9.

71. Beldman TF, Teunisse HA, Schouten TJ: Septic arthritis of the hip by Fusobacterium necrophorum after tonsillectomy: a form of Lemierre syndrome. Eur J Paediatr 1997, 156(11):856-857.

72. Kubota M, Honda K, Izumi Y, Hanada N, Katagiri M, Yanase N, Tomita T: A case of Fusobacterium necroforum sepsis. Nihon Kyobu Shikkan Gakkai Zasshi 1994, 32(11):1083-1087.

73. Blok WL, Meis JF, Gyssens IC, Gimbrere JS, Horrevorts AM: Postanginal sepsis caused by Fusobacterium necrophorum: Lemierre syndrome. Nederlands Tijdschr Geneeskds 1993, 137(20):1013-1016.

74. Weesner CL, Cisek JE: Lemierre syndrome: the forgotten disease. Ann Emerg Med 1993, 22(2):256-258.

75. Vogel LC, Boyer KM: Metastatic complications of Fusobacterium necrophorum sepsis: 2 cases of Lemierre's postanginal septicaemia. Am J Dis Child 1980, 134(4):356-358.

76. Kamath SS, Mason K: ECMO in a patient with Fusobacterium sepsis: a case report and literature review. Ann Thorac Cardiovasc Surg 2011, 17(4):397-399

77. Riordan T: Human infection with Fusobacterium necrophorum (Necrobacillosis), with a focus on Lemierre's syndrome. Clin Microbiol Rev 2007, 20(4):622-659.

doi:10.1186/1749-7922-9-38

Cite this article as: Bird et al:: Lemierre's disease: a case with bilateral iliopsoas abscesses and a literature review. World Journal of Emergency Surgery 2014 9:38.

\section{Submit your next manuscript to BioMed Central and take full advantage of:}

- Convenient online submission

- Thorough peer review

- No space constraints or color figure charges

- Immediate publication on acceptance

- Inclusion in PubMed, CAS, Scopus and Google Scholar

- Research which is freely available for redistribution 